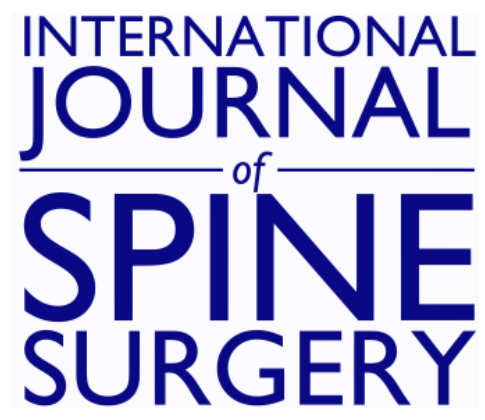

\title{
Augmented Reality Navigated Sacral-Alar-Iliac Screw Insertion
}

Cyrill Dennler, Nico Akhavan Safa, David Ephraim Bauer, Florian Wanivenhaus, Florentin Liebmann, Tobias Götschi and Mazda Farshad

Int J Spine Surg 2021, 15 (1) 161-168

doi: https://doi.org/10.14444/8021

http://ijssurgery.com/content/15/1/161

This information is current as of April 26, 2023.

Email Alerts Receive free email-alerts when new articles cite this article. Sign up at: http://ijssurgery.com/alerts 


\title{
Augmented Reality Navigated Sacral-Alar-lliac Screw Insertion
}

\author{
CYRILL DENNLER, MD,${ }^{1}$ NICO AKHAVAN SAFA, ${ }^{1}$ DAVID EPHRAIM BAUER, MD,${ }^{1}$ FLORIAN

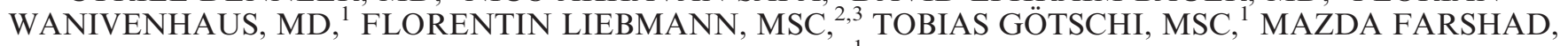 \\ $\mathrm{MD}, \mathrm{MPH}^{1}$ \\ ${ }^{I}$ Department of Orthopedics, University Hospital Balgrist, University of Zürich, Zürich, Switzerland, ${ }^{2}$ Computer Assisted Research and Development Group, \\ University Hospital Balgrist, University of Zürich, Zürich, Switzerland, ${ }^{3}$ Laboratory for Orthopaedic Biomechanics, ETH Zürich, Zürich, Switzerland
}

\begin{abstract}
Background: Sacral-alar-iliac (SAI) screws are increasingly used for lumbo-pelvic fixation procedures. Insertion of SAI screws is technically challenging, and surgeons often rely on costly and time-consuming navigation systems. We investigated the accuracy and precision of an augmented reality (AR)-based and commercially available head-mounted device requiring minimal infrastructure.

Methods: A pelvic sawbone model served to drill pilot holes of 80 SAI screw trajectories by 2 surgeons, randomly either freehand $(\mathrm{FH})$ without any kind of navigation or with AR navigation. The number of primary pilot hole perforations, simulated screw perforation, minimal axis/outer cortical wall distance, true sagittal cranio-caudal inclination angle (tSCCIA), true axial medio-lateral angle, and maximal screw length (MSL) were measured and compared to predefined optimal values.

Results: In total, $1 / 40(2.5 \%)$ of AR-navigated screw hole trajectories showed a perforation before passing the inferior gluteal line compared to $24 / 40(60 \%)$ of FH screw hole trajectories $(P<.05)$. The differences between FH- and AR-guided holes compared to optimal values were significant for tSCCIA with $-10.8^{\circ} \pm 11.77^{\circ}$ and $\mathrm{MSL}-65.29 \pm 15$ $\mathrm{mm}$ vs $55.04 \pm 6.76 \mathrm{~mm}(P=.001)$.

Conclusions: In this study, the additional anatomical information provided by the AR headset and the superimposed operative plan improved the precision of drilling pilot holes for SAI screws in a laboratory setting compared to the conventional FH technique. Further technical development and validation studies are currently being performed to investigate potential clinical benefits of the AR-based navigation approach described here.
\end{abstract}

Level of Evidence: 4.

New Technology

Keywords: augmented reality, mixed reality, navigation, sacral-alar-iliac, lumbo-pelvic fixation, HoloLens

\section{BACKGROUND}

The lumbosacral transition is a critical area for surgical fixation in adult and pediatric spine surgery. ${ }^{1-11}$ A primarily stable fixation is mandatory to avoid complications including pseudarthrosis or failure of the construct. ${ }^{12}$ Extension to the lumbopelvic region provides additional stability to lumbosacral fixation in biomechanical models and good 5-year clinical long-term outcome. ${ }^{13-16}$ Classical lumbo-pelvic fixation with iliac screws is, however, associated with mechanical irritation by prominent screw heads and difficulties in rod placement and alignment, resulting from screw head offset. ${ }^{17}$ Sacral-alar-iliac screws (SAI) crossing the sacroiliac joint described by Sponseller et $\mathrm{al}^{18}$ and Chang et $\mathrm{al}^{19}$ avoid wide dissection as well as implant prominence. As a result of the screws' lengths being between 80 and $100 \mathrm{~mm}$ and the fact that multiple layers of cortical bone are being perforated, SAI screws maximize pullout forces and therefore stability of the construct, in particular when perforation of the inner and outer iliac cortex can be avoided. ${ }^{20-22}$ Incorrect screw placement may result in injury to the obturator nerve, lumbosacral trunk, iliopsoas muscle, or internal iliac vessels in case of anterior cortex breach or injury to the superior gluteal artery in case of inferior breach. ${ }^{23}$ As initially described, insertion of SAI screws can be performed using bony landmarks to identify the correct trajectory and entry point $1 \mathrm{~mm}$ inferior and lateral to the $\mathrm{S} 1$ dorsal foramen, aiming laterally about $40^{\circ}$ in the axial plane and $20^{\circ}$ to $25^{\circ}$ caudally in the sagittal plane. ${ }^{24-26}$ The freehand $(\mathrm{FH})$ technique described by Shillingford et $\mathrm{al}^{24}$ and 


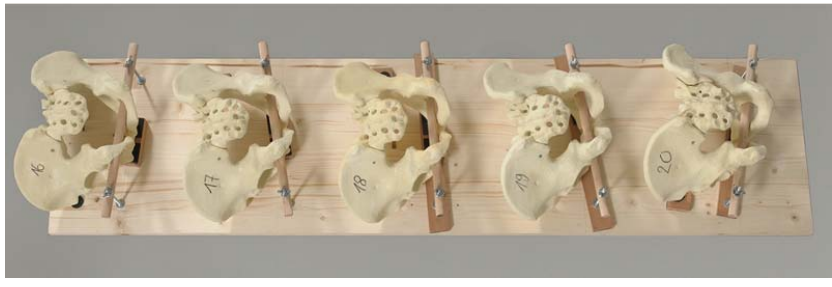

Figure 1. Pelvic models mounted to a wooden board with different angulations and tilts.

O'Brien et $\mathrm{al}^{26}$ proved to be a reliable method for screw insertion. However, to increase precision and avoid complications of screw misplacement, intraoperative 2D fluoroscopy or 3D computed tomography $(\mathrm{CT})$-based navigation are used by a majority of surgeons. ${ }^{24,26,27}$ Percutaneous and robotic techniques are also described but require extensive investments in infrastructure. ${ }^{28,29}$ Augmented reality (AR) is an emerging technology requiring minimal infrastructure that provides the viewer with additional holographic information overlaid onto the present reality via monitor-based display systems, head-mounted devices, or video see-through systems. Directly projecting the navigation guidance onto the surgical field is considered the natural progression of well-established methods mitigating the errors associated with attention shift. ${ }^{30,31}$

AR can be used for image-guided surgical interventions and was already introduced in different experimental medical and surgical settings. ${ }^{32-45}$ The use of AR in spine surgery has recently been propagated by various authors and use cases, including percutaneous vertebroplasty. ${ }^{46}$ AR-guided pedicle screw placement showed promising results in in situ studies. ${ }^{31}$ The aim of this study was to investigate the feasibility of AR-guided navigation for SAI screw insertion.

\section{MATERIALS AND METHODS}

For this experimental study, 40 male plastic pelvic models (full male pelvis solid foam, SKU \#1301, Sawbones Europe AB, Malmö, Sweden) were mounted to a wooden board in different tilting angles. The range of tilt angles was determined by examining intraoperative images from image intensifiers of SAI fixation interventions. The tilt angle was then measured between the plywood and the dorsal plane of the sacrum and ranged between $30^{\circ}$ and $52.5^{\circ}$. The axial deviation in which the pelvises were set ranged between $0^{\circ}$ and $15^{\circ}$.

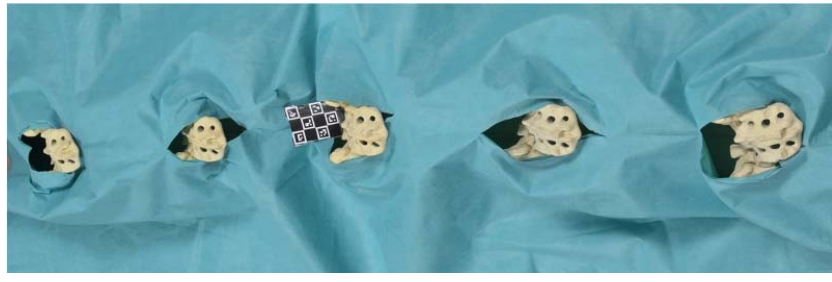

Figure 2. Pelvic models covered with a surgical drape.

For the experiment, the pelvises were covered with a surgical drape to simulate optical obstruction by soft tissues. The sacrum was left free, similar to an open posterior lumbosacral surgery (Figure 1).

A virtual 3D model of the pelvis was created (Figure 2) (Invesalius, CTI Open Labs Renato Archer, São Paulo, Brazil). ${ }^{47}$ The optimized drill hole trajectories were planned using 3D planning software (CASPA, Computer Assisted Surgical Planning Application, Balgrist CARD AG, Zürich, Switzerland). The 3D model, including optimized screw trajectories, was then uploaded to an AR head-mounted device (Microsoft HoloLens; Microsoft Corp, Redmond, Washington) (Figure 3). The left and right sides of the 40 pelvic models were randomized into 2 groups using the randomize function in Microsoft Excel version 2016 (Microsoft Corp) for either FH- or ARguided screw insertion, resulting in 80 screw holes to be drilled.

One board-certified orthopedic surgeon and one board-certified neurosurgeon, both fellowship trained in spine surgery, drilled 20 pilot holes with the conventional FH technique and 20 pilot holes with the AR technique by overlaying the virtual 3D model with screw trajectories onto the pelvic saw

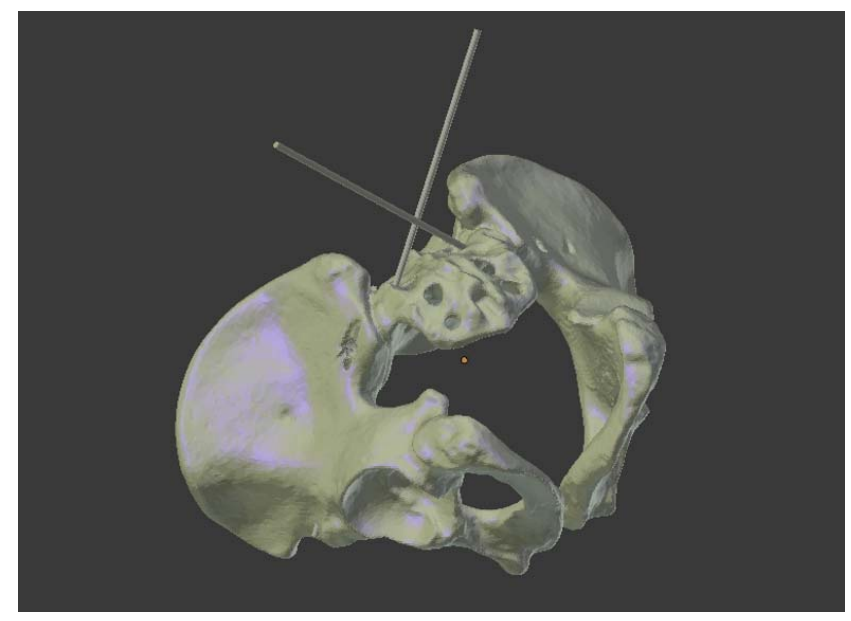

Figure 3. 3D model of a pelvis, segmented from computed tomography data, with screw trajectories. 


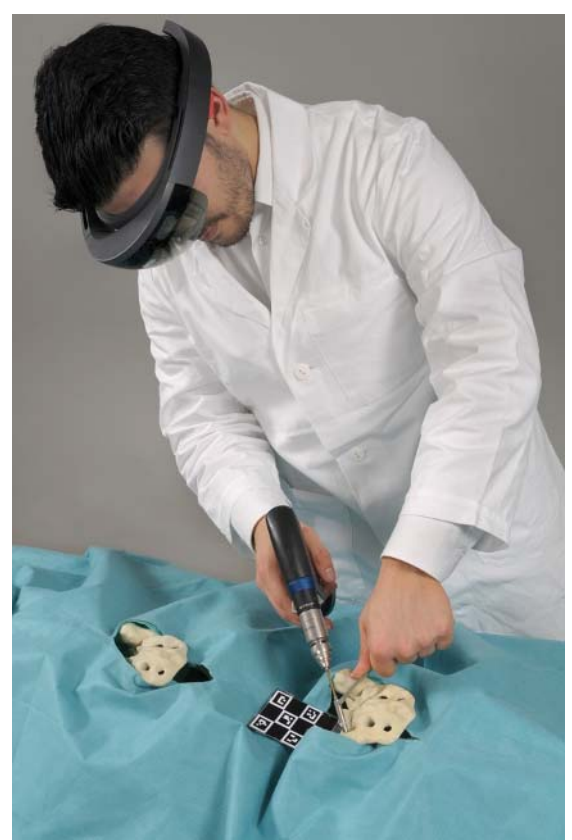

Figure 4. Surgeon drilling a pilot hole with augmented reality navigation for a sacral-alar-iliac screw.

bone model (Figures 4 and 5). This allowed the surgeons to see the preoperative planning throughout the whole drilling process in real time and $3 \mathrm{D}$ space. Also, with this 3D overlay, the otherwise hidden part of the pelvis became visible to the surgeon. The holographic projection was registered continuously by the Microsoft HoloLens using an AruCo marker ${ }^{48,49}$ that was attached to the pelvis using thermoplastic modeling clay (Figure 5). The surgeons were instructed to drill SAI pilot holes from the appropriate entry point at the lateral border and between the first and second dorsal sacral foramina along an ideal path that was defined in advance in the 3D model. For the FH group, images of the ideal screw trajectories were printed on paper and aided as a surgical plan. A perforation of the cortex before passing the inferior gluteal line had to be avoided while the longest possible screw trajectory had to be reached.

The ideal screw angles were measured within the segmented 3D model of the pelvis and transferred onto the 3D model as visible screw trajectories. For the FH group, printouts of these 3D models were provided to the surgeons.

After drilling the pilot holes with a $2.5-\mathrm{mm}$ drill bit, the drill holes were marked with $2.0-\mathrm{mm}$ pencil leads (Caran d'Ache, Geneva, Switzerland), and CT scans of the pelvises were obtained to determine the drill hole trajectory.

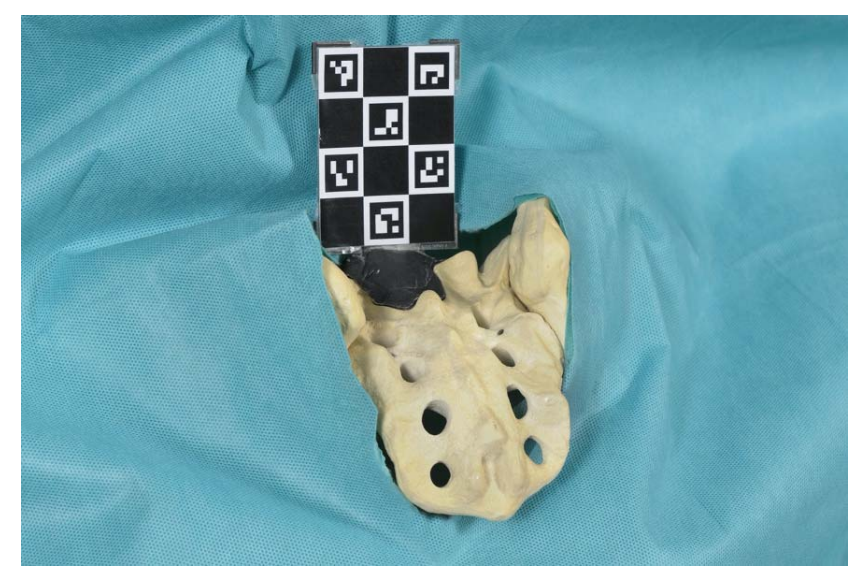

Figure 5. AruCo marker placed on pelvis to be drilled.

The number of primary pilot hole perforations (PPHP), simulated screw perforation (SSP), minimal axis to outer cortical wall distance (MAWD), true sagittal cranio-caudal inclination angle (tCCIA), true axial medio-lateral angle (tMLA), and maximal screw length (MSL) were measured (Phönix Merlin PACS, Freiburg, Germany). The subsequent analysis of the screw trajectory was performed relative to predefined planes as illustrated in Figure 6. Simulated screw perforation was defined as a calculated measure indicating cortical perforation simulating occupation of the pilot holes with screws of 8-, 9-, and 10-mm diameters.

MAWD was measured between the axis of the drill hole and the anterior and posterior cortex of the pelvic model at their closest point of approximation. Larger values indicate a more centered drill hole trajectory in between the cortical boundaries of the iliac wing.

CCIA was measured inside the 3D model as the angle between the axial plane and the drill/screw trajectory inside the 3D model. Positive CCIA correlated with a more caudal direction of the

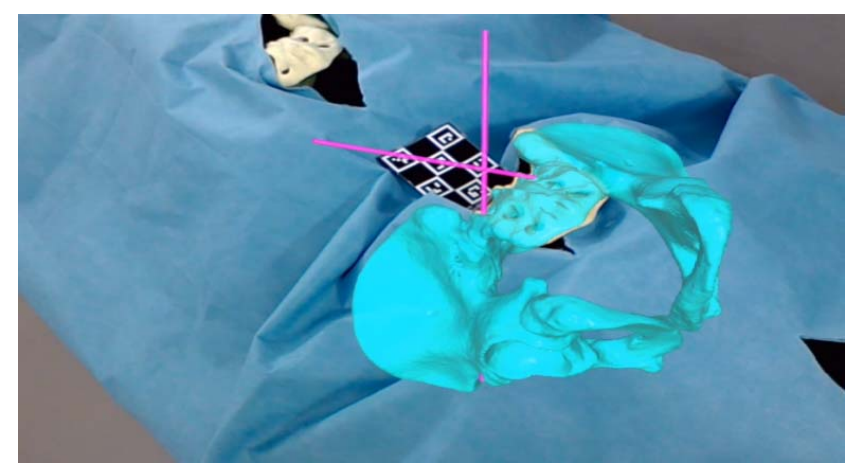

Figure 6. View from of the surgeon. Draped pelvises with an overlay of a virtual 3D pelvis (blue) including the screw trajectories (purple). 
Table 1. Number of PPHP and SSP for simulated 8-, 9-, and 10-mm screws.

\begin{tabular}{lccc}
\hline No. of Perforations for: & FH, $\mathbf{n}$ & AR, $\mathbf{n}$ & $\boldsymbol{P}$ Value \\
\hline Pilot hole & 24 & 1 & $<.001$ \\
Simulated 8-mm screw & 26 & 2 & \\
Simulated 9-mm screw & 27 & 4 & \\
Simulated 10-mm screw & 30 & 4 &
\end{tabular}

Abbreviations: AR, augmented reality; FH, freehand; PPHP, primary pilot hole perforations; SSP, simulated screw perforations.

screw. The optimal CCIA was defined as $16.02^{\circ}$ for the right drill trajectory (respectively, $18.94^{\circ}$ for the left drill trajectory) to achieve optimal screw/wall distance as well to maximize the screw length within the iliac bone (Table 2).

The true axial medio-lateral angle (tMLA) was measured inside the 3D model as the angle between the sagittal plane and the drill trajectory. The optimal medio-lateral angle was defined as $38.45^{\circ}$ for the right drill trajectory (respectively, $39.88^{\circ}$ for the left drill trajectory) to achieve optimal screw/ wall distance as well to maximize the screw hole length within the iliac bone (Table 2).

MSL was defined by measuring the length between the entry point and the farthest possible breach point of the drill trajectory within the 3D model of the pelvis. The highest achievable value for MSL for the right drill trajectory was found to be $137.5 \mathrm{~mm}$ (respectively, $142.4 \mathrm{~mm}$ for the left optimal drill trajectory) (Table 2).

The difference between the optimal and the true angles were calculated by subtracting the true from optimal angles (prefix: d). The deviation analysis was performed by first analyzing the deviation with respect to the variable and side. As the results could be weighted the same, a pooled analysis was performed.

Statistical analysis was performed using IBM SPSS Statistics version 25 (IBM Corp, Armonk, New York). A $P$ value $<.05$ was considered a statistically significant difference. The KolmogorovSmirnov test was employed to test the distribution of metric parameters. The chi-square test was performed to compare differences between categorical variables. In case of normal distribution, the Student $t$ test was applied to compare differences of continuous variables between groups. The MannWhitney $U$ test was used to compare continuous variables in case of nonnormal distribution.

\section{RESULTS}

After randomization, 40 pilot holes were drilled using the FH technique and 40 pilot holes using the
Table 2. Results of true and optimal drill hole trajectories.

\begin{tabular}{lrrrrrrrr}
\hline & \multicolumn{4}{c}{ True Measures } & & \multicolumn{1}{c}{ Optimal Measures } \\
\cline { 2 - 4 } & $\begin{array}{c}\text { Right } \\
\text { FH }\end{array}$ & $\begin{array}{c}\text { Right } \\
\text { AR }\end{array}$ & $\begin{array}{c}\text { Left } \\
\text { FH }\end{array}$ & $\begin{array}{c}\text { Left } \\
\text { AR }\end{array}$ & & Right & Left \\
\hline CCIA, & 5.0 & 11.9 & 8.2 & 15.0 & 16.0 & 18.9 \\
MLA, & 37.7 & 41.6 & 41.96 & 41.52 & & 38.45 & 39.88 \\
MSL, mm & 70.1 & 85.5 & 79.2 & 84.3 & & 137.5 & 142.4 \\
\hline
\end{tabular}

Abbreviations: AR, augmented reality; CCIA, cranio-caudal angle; MLA, mediolateral angle; MSL, maximal screw length; $\mathrm{FH}$, freehand.

AR technique. No significant differences in pilot hole trajectory or number of perforations were recorded when comparing the results of individual surgeons. In total, $1 / 40(2.5 \%)$ of AR-guided screw hole placements showed a perforation before passing the inferior gluteal line compared to $24 / 40$ $(60 \%)$ FH screw hole placements $(P<.05)$. Accuracy of AR-guided screw hole placement was significantly higher compared to FH screw placement (Table 1).

MAWD using the $\mathrm{FH}$ technique was $5.5 \pm 2.9$ $\mathrm{mm}$ vs $7.3 \pm 1.9 \mathrm{~mm}$ in the AR group. After calculation the SSP using MAWD, 26 screws in the FH group vs 2 screws in the AR group with 8-mm diameter, 27 screws in the FH group vs 4 screws in the AR group with 9-mm diameter, and 30 screws in the FH group vs 4 screws in the AR group with $10-\mathrm{mm}$ diameter revealed cortical perforation (Table 1).

CCIA for the right screw hole placement using the $\mathrm{FH}$ technique was $5.0^{\circ} \pm 12.1^{\circ}$ vs $\mathrm{AR} 11.9^{\circ} \pm$ $3.1^{\circ}$ and $\mathrm{FH} 8.2^{\circ} \pm 11.8^{\circ}$ vs AR $15.0^{\circ} \pm 4.3^{\circ}$ for the left screw hole placement, respectively. The difference in cranio-caudal angle (dCCIA) was $-10.8^{\circ} \pm$ $11.77^{\circ}$ in the $\mathrm{FH}$ group and $-3.98^{\circ} \pm 3.68^{\circ}$ in the AR group $(P=.001)$.

The tMLA for the right screw hole placement using the $\mathrm{FH}$ technique was $37.7^{\circ} \pm 3.8^{\circ}$ vs $\mathrm{AR}$ $41.6^{\circ} \pm 2.8^{\circ}$. The tMLA for the left screw hole placement using the $\mathrm{FH}$ technique was $41.96^{\circ} \pm 5.1^{\circ}$ vs AR $41.52^{\circ} \pm 2.8^{\circ}$. The difference in medio-lateral angle (dMLA) was FH $0.7^{\circ} \pm 4.65^{\circ}$ and AR $2.4^{\circ} \pm$ $2.9^{\circ}(P=.051)$.

The true maximal screw length for the right screw hole placement using the $\mathrm{FH}$ technique was $70.1 \pm$ $17.4 \mathrm{~mm}$ vs AR $85.5 \pm 4.9 \mathrm{~mm}$ and FH $79.2 \pm 12.2$ $\mathrm{mm}$ vs $\mathrm{AR} 84.3 \pm 7.1 \mathrm{~mm}$ for the left screw hole placement (Table 2). The difference in maximal screw length (dMSL) was FH $-65.29 \pm 14.99 \mathrm{~mm}$ and AR $-55.04 \pm 6.76 \mathrm{~mm}(P=.001)$. The differences between the optimal and true values are illustrated in Table 3. 
Table 3. Deviation of screw parameters.

\begin{tabular}{lccc}
\hline & FH & AR & P Value \\
\hline dCCIA, mean \pm SD, ${ }^{\circ}$ & $-10.8 \pm 11.7$ & $-3.98 \pm 3.68$ & .001 \\
dMLA, mean \pm SD, ${ }^{\circ}$ & $0.7 \pm 4.65$ & $2.4 \pm 2.9$ & .051 \\
dMSL, mean \pm SD, mm & $-65.29 \pm 14.99$ & $-55.04 \pm 6.76$ & .001 \\
\hline
\end{tabular}

Abbreviations: AR, augmented reality; dCCIA, difference in cranio-caudal angle; dMLA, difference in medio-lateral angle; dMSL, difference in maximal screw length; $\mathrm{FH}$, freehand.

\section{DISCUSSION}

Achieving a solid arthrodesis across the lumbosacral transition zone is challenging. ${ }^{50}$ Extending fusion to the iliac region increases biomechanical stability and therefore facilitates lumbosacral fusion. ${ }^{14}$ SAI screw fixation is a reliable but technically demanding technique for lumbosacral fixation in spine surgery. However, screw misplacement may result in neurovascular injury or screw loosening as a result of insufficient bone purchase. ${ }^{23}$ Recent experimental, cadaveric, and in situ studies demonstrate improved accuracy with AR-facilitated thoraco-lumbar and sacral pedicle screw placement. ${ }^{31}$ However, so far, data on sacroiliac screw placement are not available. The subject of this study was the feasibility of AR navigation in regard to accuracy and precision for the placement of SAI screws in an experimental setting.

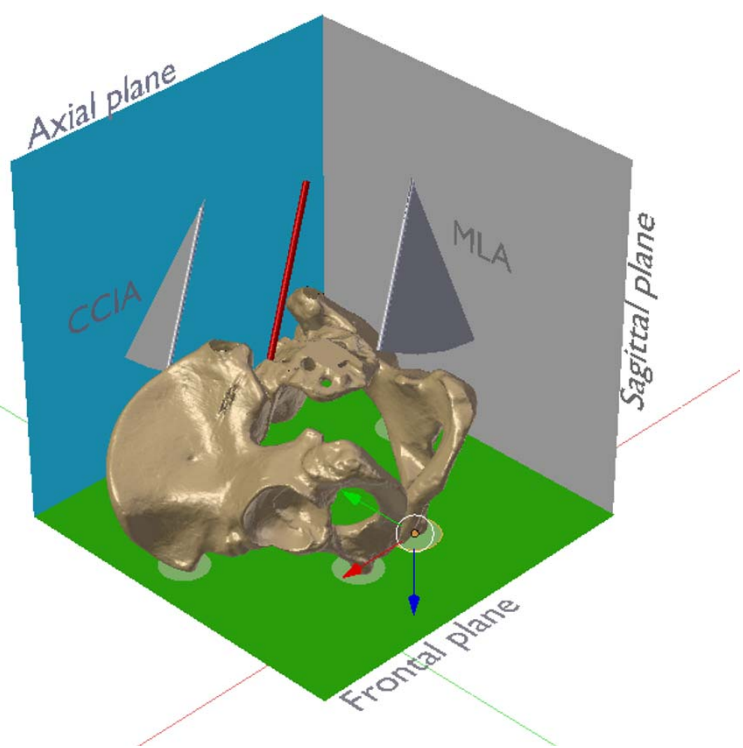

Figure 7. Pelvis and left sacral-alar-iliac drill axis (red). The anterior pelvic plane, defined by the anterior superior iliac spines and the pubic tubercles (all in green circles), was defined as the frontal plane (green). The axial plane (blue) was defined as perpendicular to both frontal and anatomical sagittal (reddish) planes. The cranio-caudal inclination angle was measured between the drill axis and the axial plane. The medio-lateral convergence angle was measured between the drill axis and the sagittal plane. The angles were measured between the axis and their orthogonal projection onto the respective plane using multiplanar reconstruction of the computed tomography data.

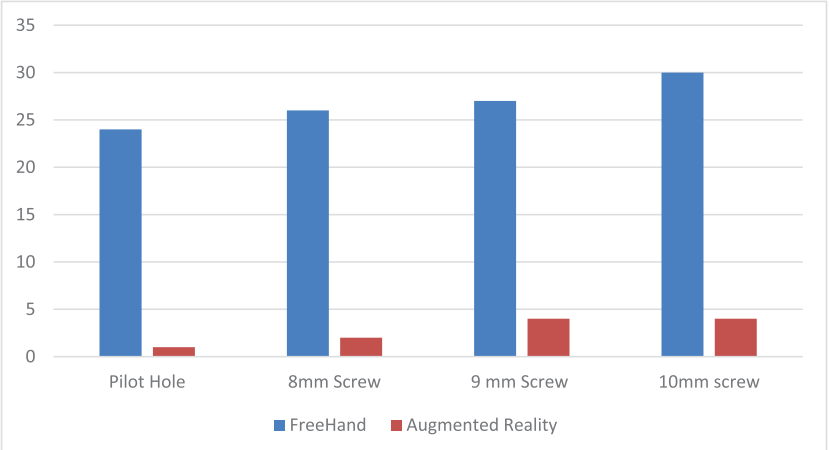

Figure 8. Real (pilot hole) and simulated numbers of bone perforations with different screw diameters.

The results of this pilot study demonstrate the feasibility of guiding surgical instruments using the AR technology with a compact head-mounted device requiring minimal infrastructure for the placement of SAI screws. In this study, AR improved precision of placement of SAI screws significantly compared to the $\mathrm{FH}$ technique. AR navigation showed a significant overall improvement in the number of primary and secondary perforations, an increased precision of the craniocaudal inclination angle and the medio-lateral angle, and an increase in MSL.

Early studies introduced the concept of ARguided placement of fixation devices in spine surgery in an experimental setting. ${ }^{46,51}$ More recently, these results could be translated into the operating room. By placing 253 pedicle screws using an AR device and an accuracy of $94.1 \%$, the authors confirmed the feasibility of this novel technique. ${ }^{31}$ ElmiTerander et $\mathrm{al}^{31}$ used a robotic ceiling-mounted Carm system to pre- and postoperatively acquire the required information for navigating screw placement and an external screen to display the obtained information. In contrast, our experimental setup used a fiducial AruCo marker for tracking, registering, and overlaying the holographic picture onto the pelvic model, theoretically avoiding the need for large and costly infrastructure inside the operating room. The tracking and overlaying process is essential when placing virtual objects into the real world in correct relations and positions. The AruCo marker is composed of a wide black border and an inner binary matrix allowing its identification and determining its rotation. Although technically possible, positioning the marker might be impractical in real-life surgery and require addition incisions. However, the technical optimization of registration methods, including automated registration by rec- 
ognizing relevant anatomical structures via machine learning, is the subject of further research and development. ${ }^{52}$

As a result of its early stage of development, preoperative planning and execution using AR still involves multiple steps requiring highly specialized personnel. For this study, preoperative planning consisted of segmentation of the 2D data acquired by the CT scans into a segmented 3D model, planning of the drill hole trajectories, and uploading the data to the AR device. Apart from relatively low direct costs of the head-mounted device and the required CT scan, these indirect costs have to be taken into consideration. However, with further evolution of the technology, simpler and more costeffective workflows can be implemented.

This study has limitations. For this analysis, 40 pelvic models with identical anatomy were used, thereby introducing the potential bias of a learning effect for the surgeon. This was accounted for by randomly tilting the pelvic models in different angles, covering relevant parts of the anatomical landmarks and randomization of the models. Further, the FH group was not provided with additional commonly available navigation aids, including an image intensifier. However, identification of the screw entry point and trajectory exclusively relies on validated bony landmarks, and perforation of the screws through the anterior or posterior cortex is avoided by palpation of the predrilled trajectory with a ball probe. ${ }^{24}$ Also, by providing the FH group with a preoperative plan depicting the ideal screw trajectory, this was at least partially accounted for.

\section{CONCLUSIONS}

In this study, the additional anatomical information provided by the AR headset and the superimposed operative plan improved the precision of drilling of pilot holes for SAI screws in a laboratory setting compared to the conventional FH technique. Further technical development and validation studies are currently being performed to investigate potential clinical benefits of the AR-based navigation approach described here.

\section{REFERENCES}

1. Kebaish KM. Sacropelvic fixation: techniques and complications. Spine (Phila Pa 1976). 2010;35(25):2245-2251.

2. Bernhardt M, Swartz DE, Clothiaux PL, Crowell RR, White AA. Posterolateral lumbar and lumbosacral fusion with and without pedicle screw internal fixation. Clin Orthop Relat Res. 1992;(284):109-115.

3. Allen BL, Ferguson RL. The Galveston technique of pelvic fixation with L-rod instrumentation of the spine. Spine (Phila Pa 1976). 1984;9(4):388-394.

4. Molinari RW, Bridwell KH, Lenke LG, Ungacta FF, Riew KD. Complications in the surgical treatment of pediatric highgrade, isthmic dysplastic spondylolisthesis. A comparison of three surgical approaches. Spine (Phila Pa 1976). 1999;24(16):17011711.

5. Grubb SA, Lipscomb HJ. Results of lumbosacral fusion for degenerative disc disease with and without instrumentation. Twoto five-year follow-up. Spine (Phila Pa 1976). 1992;17(3):349-355.

6. Lenke LG, Bridwell KH, Bullis D, Betz RR, Baldus C, Schoenecker PL. Results of in situ fusion for isthmic spondylolisthesis. J Spinal Disord. 1992;5(4):433-442.

7. Schwab FJ, Nazarian DG, Mahmud F, Michelsen CB. Effects of spinal instrumentation on fusion of the lumbosacral spine. Spine (Phila Pa 1976). 1995;20(18):2023-2028.

8. Leong JCY, Lu WW, Zheng Y, Zhu Q, Zhong S. Comparison of the strengths of lumbosacral fixation achieved with techniques using one and two triangulated sacral screws. Spine (Phila Pa 1976). 1998;23(21):2289-2294.

9. Alegre GM, Gupta MC, Bay BK, Smith TS, Laubach JE. S1 screw bending moment with posterior spinal instrumentation across the lumbosacral junction after unilateral iliac crest harvest. Spine (Phila Pa 1976). 2001;26(18):1950-1955.

10. Alegre GM, Gupta MC, Bay BK, Smith TS, Laubach JE. S1 screw bending moment with posterior spinal instrumentation across the lumbosacral junction after unilateral iliac crest harvest. Spine (Phila Pa 1976). 2001;26(18):1950-1955.

11. Stovall DO, Goodrich JA, Lundy D, Standard SC, Joe C, Preston CD. Sacral fixation technique in lumbosacral fusion. Spine (Phila Pa 1976). 1997;22(1):32-37.

12. Ould-Slimane M, Miladi L, Rousseau MA, et al. Sacropelvic fixation with iliosacral screws: applications and results in adult spinal deformities. $J$ Spinal Disord Tech. 2013;26(4):212-217.

13. Tis JE, Helgeson M, Lehman RA, Dmitriev AE. A biomechanical comparison of different types of lumbopelvic fixation. Spine (Phila Pa 1976). 2009;34(24):866-872.

14. BW C, Lewis S, Long J, AE D, Linville D, KH B. Biomechanical evaluation of lumbrosacral reconstruction techniques for spondylolisthesis: an in vitro porcine model. Spine (Phila Pa 1976). 2002;27(21):2321-2327.

15. Lee BS, Walsh KM, Healy AT, et al. Biomechanics of L5/S1 in long thoracolumbosacral constructs: a cadaveric study. Global Spine J. 2018;8(6):607-614.

16. Tsuchiya K, Bridwell KH, Kuklo TR, Lenke LG, Baldus C. Minimum 5-year analysis of L5-S1 fusion using sacropelvic fixation (bilateral $\mathrm{S} 1$ and iliac screws) for spinal deformity. Spine (Phila Pa 1976). 2006;31(3):303-308.

17. Ishida W, Elder BD, Holmes C, et al. S2-alar-iliac screws are associated with lower rate of symptomatic screw prominence than iliac screws: radiographic analysis of minimal distance from screw head to skin. World Neurosurg. 2016;93:253-260.

18. Sponseller PD, Zimmerman RM, Ko PS, et al. Low profile pelvic fixation with the sacral alar iliac technique in the pediatric population improves results at two-year minimum follow-up. Spine (Phila Pa 1976). 2010;35(20):1887-1892.

19. Chang T-L, Sponseller PD, Kebaish KM, Fishman EK. 
Low profile pelvic fixation. Spine (Phila Pa 1976). 2009;34(5):436-440.

20. Ishida $\mathrm{W}$, Elder $\mathrm{BD}$, Holmes $\mathrm{C}$, et al. Comparison between S2-alar-iliac screw fixation and iliac screw fixation in adult deformity surgery: reoperation rates and spinopelvic parameters. Global Spine J. 2017;7(7):672-680.

21. Shabtai L, Andras LM, Portman M, et al. Sacral alar iliac (SAI) screws fail 75\% less frequently than iliac screws in neuromuscular scoliosis. J Pediatr Orthop. 2017;37(8):e470e475.

22. Shin JK, Lim B, Goh TS, et al. Effect of the screw type (S2-alar-iliac and iliac), screw length, and screw head angle on the risk of screw and adjacent bone failures after a spinopelvic fixation technique: a finite element analysis. PLoS One. 2018;13(8):1-21.

23. Abdul-Jabbar A, Yilmaz E, Iwanaga J, et al. Neurovascular relationships of S2AI screw placement: anatomic study. World Neurosurg. 2018;116:e108-e112.

24. Shillingford JN, Laratta JL, Tan LA, et al. The free-hand technique for S2-alar-iliac screw placement. J Bone Jt Surg Am. 2018;100(4):334-342.

25. Park YS, Hyun SJ, Park JH, Kim KJ, Jahng TA, Kim HJ. Radiographic and clinical results of freehand S2 alar-iliac screw placement for spinopelvic fixation. Clin Spine Surg. 2017;30(7):E877-E882.

26. O'Brien JR, Yu WD, Bhatnagar R, Sponseller P, Kebaish KM. An anatomic study of the S2 iliac technique for lumbopelvic screw placement. Spine (Phila Pa 1976). 2009;34(12):E439-E442.

27. Shillingford JN, Laratta JL, Tan LA, et al. The free-hand technique for S2-alar-iliac screw placement. J Bone Jt Surg Am. 2018;100(4):334-342.

28. El Dafrawy MH, Kebaish KM. Percutaneous S2 alar iliac fixation for pelvic insufficiency fracture. Orthopedics. 2014;37(11):e1033-e1035.

29. Bederman SS, Hahn P, Colin V, Kiester PD, Bhatia NN. Robotic guidance for S2-alar-iliac screws in spinal deformity correction. Clin Spine Surg. 2017;30(1):E49-E53.

30. Molina CA, Theodore N, Ahmed AK, et al. Augmented reality-assisted pedicle screw insertion: a cadaveric proof-ofconcept study. J Neurosurg Spine. 2019;31(1):1-8.

31. Elmi-Terander A, Burström G, Nachabe R, et al. Pedicle screw placement using augmented reality surgical navigation with intraoperative 3D imaging: a first in-human prospective cohort study. Spine (Phila Pa 1976). 2019;44(7):517-525.

32. Edwards PJ, Hawkes DJ, Hill DLG, et al. Augmentation of reality using an operating microscope for otolaryngology and neurosurgical guidance. Comput Aided Surg. 1995;1(3):172178.

33. Edwards P, Hill D, Little J, Sahni V, Hawkes D. Medical image registration incorporating deformations. In: Proceedings of the British Machine Vision Conference 1995. British Machine Vision Association; 1995. p. 69.1-69.10.

34. Cabrilo I, Bijlenga P, Schaller K. Augmented reality in the surgery of cerebral aneurysms: a technical report. Neurosurgery. 2014;10(2):252-261.

35. Gavaghan KA, Peterhans M, Oliveira-Santos T, Weber S. A portable image overlay projection device for computer-aided open liver surgery. IEEE Trans Biomed Eng. 2011;58(6):18551864.

36. Chen X, Xu L, Wang Y, et al. Development of a surgical navigation system based on augmented reality using an optical see-through head-mounted display. $J$ Biomed Inform. 2015;55:124-131.

37. Watanabe E, Satoh M, Konno T, Hirai M, Yamaguchi T. The Trans-Visible Navigator: a see-through neuronavigation system using augmented reality. World Neurosurg. 2016;87:399405.

38. Edwards PJ, Johnson LG, Hawkes DJ, Fenlon MR, Strong AJ, Gleeson MJ. Clinical experience and perception in stereo augmented reality surgical navigation. 2004. p. 369-376.

39. Sauer F, Wenzel F, Vogt S, Tao Y, Genc Y, BaniHashemi A. Augmented workspace: designing an AR testbed. In: Proceedings IEEE and ACM International Symposium on Augmented Reality (ISAR 2000). IEEE; p. 47-53.

40. Sauer F, Khamene A, Bascle B, Schinunang L, Wenzel F, Vogt S. Augmented reality visualization of ultrasound images: system description, calibration, and features. In: Proceedings IEEE and ACM International Symposium on Augmented Reality. IEEE Comput. Soc; p. 30-39.

41. Birkfellner W, Figl M, Huber K, et al. A head-mounted operating binocular for augmented reality visualization in medicine - design and initial evaluation. IEEE Trans Med Imaging. 2002;21(8):991-997.

42. Fuchs H, Livingston MA, Raskar R, et al. Augmented reality visualization for laparoscopic surgery. 1998. p. 934-943.

43. Traub J, Stefan P, Heining SM, et al. Towards a hybrid navigation interface: comparison of a slice based navigation system with in-situ visualization. 2006;179-186.

44. Traub J, Stefan P, Heining SM, et al. Hybrid navigation interface for orthopedic and trauma surgery. Med Image Comput Comput Assist Interv. 2006;9(pt 1):373-380.

45. Traub J, Stefan P, Heining SM, et al. Lehrstuhl für Informatikanwendungen in der Medizin \& Augmented Reality. 2018.

46. Abe Y, Sato S, Kato K, et al. A novel 3D guidance system using augmented reality for percutaneous vertebroplasty. J Neurosurg Spine. 2013;19(4):492-501.

47. Amorim P, Moraes T, Silva J, Pedrini H. InVesalius: An Interactive Rendering Framework for Health Care Support. 2015. p. 45-54.

48. Romero-Ramirez FJ, Muñoz-Salinas R, Medina-Carnicer R. Speeded up detection of squared fiducial markers. Image Vis Comput. 2018;76:38-47.

49. Garrido-Jurado S, Muñoz-Salinas R, Madrid-Cuevas FJ, Medina-Carnicer R. Generation of fiducial marker dictionaries using mixed integer linear programming. Pattern Recognit. 2016;51:481-491.

50. Weistroffer JK, Perra JH, Lonstein JE, Schwender JD, Garvey TA, Transfeldt EE, et al. Complications in long fusions to the sacrum for adult scoliosis: Minimum five-year analysis of fifty patients. Spine (Phila Pa 1976). 2008;33(13):1478-1483.

51. Bichlmeier C, Navab N, Heining SM, Feuerstein M. The virtual mirror: a new interaction paradigm for augmented reality environments. IEEE Trans Med Imaging. 2009;28(9):1498-1510.

52. Liebmann F, Roner S, von Atzigen M, et al. Pedicle screw navigation using surface digitization on the Microsoft HoloLens. Int J Comput Assist Radiol Surg. 14(7):1157-1165.

53. Gerrand C. CORR Insights ${ }^{\circledR}$ : Can augmented reality be helpful in pelvic bone cancer surgery? An in vitro study. Clin Orthop Relat Res. 2018;476(9):1726-1727.

Disclosures and COI: Cyrill Dennler and Nico Akhavan Safa contributed equally to this 
publication. The project was funded by the Balgrist University Hospital, which receives funding from different sources. The authors did not receive separate funding for this project. One of the authors (MF) declared a potential conflict of interest, as he is the founder of two spin-off companies for AR surgical navigation. However, there is no direct conflict of interest concerning this article. For the remaining authors, none were declared.

Corresponding Author: Cyrill Dennler, Dr Med, Department of Orthopedics, University Hos- pital Balgrist, University of Zürich, Forchstrasse 340, 8008 Zürich, Switzerland. Phone: +41 4438611 11; Fax: +41 4438611 09; Email: cyrill.dennler@ gmail.com.

Published 26 February 2021

This manuscript is generously published free of charge by ISASS, the International Society for the Advancement of Spine Surgery. Copyright (C) 2021 ISASS. To see more or order reprints or permissions, see http://ijssurgery.com. 